\title{
Promotion of Indigenous Knowledge through Scientific Research is Fundamental to Sustainable Development: An Anthropological Perspective
}

\author{
Senait Bahta \\ Department of Anthropology and Archaeology, Adi- Keih College of Arts and Social Sciences, Eritrea
}

Copyright $\mathrm{C} 2017$ by authors, all rights reserved. Authors agree that this article remains permanently open access under the terms of the Creative Commons Attribution License 4.0 International License

\begin{abstract}
Human societies generate knowledge and strategies enabling them to survive in balanced relations with their natural and social environments. All societies thus, have their own indigenous knowledge systems originated from life's experiences. This indigenous knowledge gives each society an identity. They are adaptive and enable them survive. They have survival value for the specific society because they were originated to serve the needs of the group and give them power to participate in decisions for their livelihood to sustain. Indeed, they are the 'genetic material' for development. Patman [1] writes, "There is a long tradition in Africa of reaching decision by unanimous consent - minority voices given a fair hearing...." Cheikh Anta Diop [2] emphasizes the need to build African human sciences, while Foucault [3] suggests, "There is a gap to feel by discovering the "Archaeology of knowledge". The researcher argues that, promotion of indigenous knowledge is fundamental to sustainable development, for, knowledge generated from local peoples' life experiences agree to the law of the land and sustains their daily life. As sustainable development is community centered, it can be rational through scientific research of traditions that successfully solved local socio-economic and political conditions. Formalizing the local knowledge system into the national curriculum so as to transmit it to the new generation will also result in enhanced identity and a better standard of living.
\end{abstract}

Keywords Indigenous Knowledge, Identity, Adaptive

\section{Introduction}

People of all societies, past and present, generate or engender knowledge while they face and tackle natural and social challenges in their communities' daily life. Such indigenous knowledge is originated from lived experiences of each particular society under a particular social and environmental condition. It is in congruence to the specific human or social and physical environment that the communities survive through developing systems of care and resource regulation. Hence, it is building these already existing systems of knowledge, of resource regulation and social control that can bring sustainable development that enhances the identity and well being of the communities, for a better standard of life. Discarding them to be replaced by other systems not adaptive to the area will just do the opposite.

In this paper it is argued that, socio-economic development that will enhance and change the low quality of life of communities in the South in general, will need scientific and collaborative interdisciplinary research of the local or indigenous knowledge systems that helped them adapt to the changes in their specific social and physical environments. Thus, the local knowledge should be transmitted to the new generations through formalizing it. Only then can sustainable development that is culture based and community centered be achieved. The argument is based on data from research in various areas including in the rich biodiversity area in western Eritrea, where much knowledge on wild plants and belief system to preserve and protect them can be observed. Also lessons are taken from Ghana, where local medicinal plant are being put into local use supplying the local communities with home made medicine that are affordable and easily accessible, compared to the imported medicine that some time is in short supply when the local community members are in need of them. So both affordability and availability added to the self esteem that is raised with home made products, not only raises the identity of local people but also their standard of life. The argument in the paper follows Ghyeke's [4] theory that development does not take place in a cultural vacuum but should be culture centered.

If we look at the indigenous systems of highland agrarian communities of Eritrea, according to local customs, a mother of twins has special right for pasture land. The community 
carries the responsibility of supporting the twins' family by allowing them pasture their cattle in the preserved land, not allowed for others. Likewise in the lowlands, the Gash Barka communities in western Eritrea practice a belief system that holds, cutting trees or even their leaves, especially from the tree called Oma in Kunama language- (Hyphaene thebatica), which is useful for making basketry, medicine and raw material, brings a curse on the person who does so. This kind of belief that the people follow, intends to save the rich biodiversity in the locality, which is a niche of great local knowledge discovery and so is relevant and useful for contemporary societies' needs. Such local systems help the local communities survive and are effective means of social control and so of survival.

These systems of knowledge vary from one place to another or from one time and society to another depending on the way of life of the particular group. For instance, communities who depend on fishing have own knowledge on preserving their marine resources. Traditionally, fishermen in the Red Sea region of Semhar in Eastern Eritrea who live by the sea coast adapting fishing as their economic activity, return the young ones from their fishing net back to the sea, so that to assure their continuity and sustain their life.

The researcher's experience during summer research visit in the University of Ghana, and the Centre for Scientific Research on Plant Medicine (CSRPM) was that there is need for cooperation in collaborative research on local knowledge and its development through formalizing it in the educational systems. The CSRPM has done an impressive task on preserving species of local plant medicine and locally producing various medicines for use by the communities through laboratory work and social research. The advantage is multiple. Besides the locally produced medicine and preservation of indigenous knowledge of plant uses, the young graduates from both the Sciences have job opportunities and so continuity with local resources and human skill is secured. Regional cooperation in this field will help a lot to develop the local resources both human and physical and lead towards self-sufficiency in all fields.

Various theoreticians and writers have elaborated the usefulness of local knowledge and their significance for sustainable development including Gyeke [4], Pateman [1], Foucault [3], Cheik Anta Diop [2] and Chambers [5], to mention some. This paper supports their theories that state that 'development takes place in a cultural setting', and 'local knowledge is a means of social control measure', and that there is much to discover on these wisdom if we excavate our history.

Gheyeke [4] writes,

The development of a human society does not take place in a vacuum; that it is within a culture

that a human being finds his/her identity and can be what he/she is or wants to be; that all human

activity springs from a cultural base and takes on, or derives, its significance from the context of that culture.... If the development activity is to come to grips with the problems of human society, then it can only do so within the culture of a society.

The main purpose of this paper is to contribute to current literature on indigenous knowledge by highlighting that locally engendered knowledge is based in the communities' life experience and has helped them survive for generation and so its value is enduring. It gives the specific group identity; Hence, the communities' development cannot be separated from developing this local systems of knowledge of social control and resource regulation through scientific research.

\section{Indigenous Knowledge and Anthropology}

According to Merriam Webster Dictionary [5], the concept 'indigenous knowledge' is defined, 'occurring naturally in a particular region or environment'. In Cultural Anthropology how this occurred is an importance research area. That human groups developed 'practical and effective ways to meet the basic needs of human existence' can be reflected in such studies. Chambers [6] argues,

One of the contributions of anthropology is to demonstrate that most human groups have developed practical and effective ways to meet the basic needs of human existence. These practices are in turn reinforced by a belief system which helps relate individual practices to a total way of being. An understanding of indigenous belief systems and the practices that accompany them is useful in a number of ways. Farming practices which seem impractical from the vantage of Western agriculture may...make more sense when viewed in their cultural context... the persistence of indigenous practices which have become maladaptive because of radical changes in the conditions of a people's existence may seem irrational, but can be better understood when associated with the cultural context from which those practices are derived.

All contemporary forums at national, regional or international stages are continuity of concerns from older days including Biodiversity Conservation, Wild Life Protection and Climate Change etc. An African elder pronounces this when he says, 'our ancestors had awareness for environmental conservation and had set rules to follow; if our ancestors did not have a system of environmental conservation, we would not have any resources to use or to live on today'. With the present condition or destruction of the environments, which is the source of our knowledge system, but also the passing of elders who own the knowledge, this resourceful human heritage can disappear unless studied and inscribed deliberately or on purpose as genetic material of sustainable development with the goal of benefitting communities who are the inheritors of this 
heritage. Anthropology of development should indeed focus on this area as a source of knowledge. Its loss will also lead to another disadvantage. Unless formalized through scientific research, new generation will not learn about their history, identity, and how in the past humans managed to survive in this planet before the advent of technological advancement.

According to Professor Pateman [1], "Customary law is an aspect of deeply held beliefs, and it is dangerous to try and marginalize it or treat it as unworthy ... Customs if used wisely, may represent a powerful instrument of social control".

In Anthropology, continuity is the issue, that is, human adaptability to the changing environments. We know that it is through cultural and biological adaptation that survival occurred and will occur, and not through detaching with the past. The present is rooted in the past, and the future is continuation of the present. Sustainable development cannot take roots without the knowledge of how people coped to survive in the past and what needs change and what should be sustained for a better life. Development means building up on what has already started by learning from the past and avoiding the harmful practices to introduce new changes that suit the local community's life. Scientific study of past wisdoms in all aspects of life can be a stepping stone towards a real sustainable development. Without developing through research our indigenous knowledge, there can be no other route to flourish the livelihood of local communities and so no way to sustainable development. Genuine effort in this area will need the collaboration of all scholars and researchers of all disciplines. Some ethnographic data can highlight the argument.

The Kunama believe that "when there are trees there is wealth'. If we destroy the trees there will not be rain, human beings cannot continue to live. Livestock will disappear. The natural resources are meant for humans and animals to use for their survival. Most important is the maintenance of trees. However, data shows that there is loss of indigenous knowledge in the younger generation including young mothers. The Kunama women say that 'Our mothers were better than us. We are better than our children and our children will be better than their children. Yet, Kunama data verifies, that indigenous knowledge is local and traditional, subsistence oriented, contextual, and communal, uncorrupted by the influence of the market, and passed on informally, and must be urgently preserved.

When asked to prioritize resources according to human survival needs, the respondents said trees come next to water as the source of life. Livestock can be purchased from selling what you produce on your land. But if trees are destroyed, there cannot be rain, livestock cannot reproduce and therefore, human life will be threatened. Their indigenous knowledge on wild plants and trees, their perception of land as a resource that is not owned by anyone but God and their egalitarian view on their female counterparts gives the community cohesion and unity. Indeed, they own a pool of knowledge that can be utilize for far greater goals and so improve human quality of life. This important indigenous knowledge can be changed into economic, social, and cultural values but only if we excavate the depth of the knowledge that the Archaeology of Knowledge suggested by other writers, through interdisciplinary research and formalize or institutionalize it.

\section{Indigenous Knowledge, Development and Scientific Research}

Comprehensive institutions such as solving conflicts with peace and reconciliation give opportunity to the rich and the needy, the offender and the plaintiff. That is why Prof. Patman [1] states in his writing, "There is a long tradition in Africa of reaching decision by unanimous consent - minority voices given a fair hearing." That calls for a scientific studying of our own institutions and applying them for local development and sustain the knowledge and institutions of the local people. It is important to note what Cheikh Anta Diop [3] emphasizes as "the need to build African human sciences" so as to teach and transmit the knowledge systems that enabled the communities survive for centuries in their local environments.

Research in this area needs to be holistic, which means it should include all fields and all sectors of the communities. For instance such knowledge especially on food and medicinal types is owned by women of all communities. UNEP report noted that women, especially in developing countries are the farmers, the feeders and the carers in their communities relying on an intimate understanding of nature to fulfil their many and varied roles. ...Female members of a community often bear the brunt of a natural disaster, such as famine or drought, and are the ones who shoulder the responsibility for keeping offspring alive'[7].

In a monograph on Selected Essays by Professor Gyeke [4], a chapter on 'Taking Development Seriously' argues, "Constructing development in terms of economic growth, international organizations...have geared most of their activities in the developing countries towards the production of material things, increase of food production, provision of electricity and good drinking water, building of roads etc. ... Similarly centers of research, called Institutes of Development, have devoted almost all of their attention to problems of economic development or economic growth. Given the complex nature of human societies and culture, however, such an economic approach or conception of development is lopsided..." Gyeke [4].

Research being studious inquiry or examination and interpretation of facts, examining indigenous knowledge for studious and development purposes is relevant. Many countries in the South including China, India, and Ghana to name some, have succeeded in formalizing IK into their educational systems and national curriculum and upgraded and liberated it for contemporary use which has resulted in 
multiple benefits for the local communities including: reasonable price of items bought for they are produced locally; job opportunities for young graduates who are involved in research and practical skills related to indigenous knowledge increase in income for the nation from the innovative work on IK.

Since the communities in the South have similar conditions of under development, it is imperative that research relations can do mutual benefit for the interacting communities across the localities. This was the experience of the researcher in Ghana. The Centre for Scientific Research in Plant Medicine (CSRPM) is located in Mampong-Akuapem near the Aburi Gardens where plants preservation takes place. It is also a tourist area. The centre is the place where local knowledge on plant medicine is researched, processed or developed and applied for local use ( $\mathrm{R}, \mathrm{D}$ and $\mathrm{A})$. At the time of the researcher's visit, the herbarium had more than 1000 species of medicinal plants were also sample plants are planted for tests. The lab is the place where the research takes place, de-moisturizing of the plant medicine, and extraction and filterization takes place here too. Then follows the testing section where the new medicines are tested, and then the pharmacologist formulates the medicine into capsules, tablets or syrups. A conclusion can be reached after an experience such as this that scientific research on IKs on plant medicine as is true in other IKs, organized across countries or regions can do much to make life better for local communities who depend totally on imported medicines, much expensive and sometimes not available.

Every community has an environment which helped them survive by offering food, medicine and tools or raw materials for their daily life. Communities in the past had knowledge of environmental conservation because they know they cannot live without their environment. Similarly the Kunama of Eritrea who live in the rich Gash Barka region say that "Our environment or the biodiversity in our environment is like our mother's breast" since no one can survive without a mother's breast or a similar nourishment or diet.

Looking at Eritrean ethnography, which may have commonalities to others' as well, almost all ethnic groups have intermingled in the past, perhaps they continue to do so at present through various interactions between the people besides internal migration, intermarriage, economic interdependence etc. The point here is, that any group big or small, rich or poor, powerful or other that, in the past, has moved to a new place with its animals and utilities, acclimatize to the law of the land where it settles. The religion, language and systems of living of their past group is not imported in the new place, rather they adopt the customs and beliefs and all ways of life of the local group.

The term for a cultural or ethnic group, a people sharing the same way of life, language and culture in the Tigrigna language is biher-followed by the name of the language of the specific group - bihere Tigrigna, or bihere Tigre,.. the last words representing the name of the language of specific group of people. There are nine distinct ethnic or cultural groups in Eritrea, and every group's name has a pre-fix biher followed by the name of the language of the group. The concept biher originally comes from Ge'ez which means land. So the name of the linguistic groups indicates at the same time the land and the people. This is to say development of the land or of the natural resources is also development of the people and its laws and all the systems that rule the land and cannot be separated. Therefore, indigenous knowledge rather than be left to be eroded should be kept alive and continue with scientific upgrading for local sustainable development.

\section{Conclusions and Recommendation}

Indigenous knowledge systems are locally acquired knowledge and practices in life experiences and are adaptive and so have survival value. To advance local or indigenous knowledge through scientific research means to flourish the life of the local people who are the owners of the local knowledge and practices. Holism has long been the hall mark of anthropology and to make the life of the people better means not only economic growth but holistically, to advance the socio-cultural conditions that surround them along with their beliefs and practices. It means to enhance their knowledge and capacity to respond adequately to the environmental conditions around them.

Since, the ultimate goal of the development of every human society is the wellbeing or the satisfaction of the basic needs of its people 4, this can be real when the indigenous knowledge of these societies is the center of the development process. The social, economic and cultural aspects should be considered, and not only the physical or infrastructural aspect of the societies. Sustainable development should aim at better living conditions of communities, which can be possible through scientific research on locally produced knowledge and strategies of survival.

Holistically, the local systems have to be upgraded to fit contemporary conditions rather than to import exogenous solution designed to respond to different conditions of life. Rather than advance the life of the society, such actions have the reverse impact on the life of the people. Indigenous knowledge system is the basis for problem-solving strategies for local communities. It represents the people and their life and their coping mechanisms and so, the relevance of essential scientific collaborative research.

\section{Acknowledgements}

I would like to thank people who supported me during the research:

- The Center for African Studies in the University of Ghana at Legon, who allowed me to have access to the library; 
- The German Embassy in Eritrea for the research fund to get recording equipment for the research, and

- Ms. Almaz Ghebray for the support she gave me by giving me accommodation in her home during my research visit in Ghana.

\section{REFERENCES}

[1] Patman, R. et al. 2003. Blood Land and Sex: Legal and Political Pluralism in Eritrea. Indiana University Press. USA.
[2] Cheik Anta Diop 1988. The African Origin of Civilization: Myth or Reality. Lawrence Hill Books.

[3] Foucault M. (1980). The Order of Things. An Archaeology of Human Sciences. Vintage Books Edition N.Y

[4] Gyeke, K 2013. Taking Development Seriously. In Philosophy, Culture and Vision. African Perspective. Sub-Saharan Publishers. Accra.

[5] Merriam Webster Dictionary. 2011. Merriam-Webster Inc.

[6] Chambers R. 1994. The Origin and Practice of Participatory Rural Appraisal. World Development.

[7] UNEP, 2004. Women in the Frontline in Quest for Sustainable Development. UNEP Press Released, May 2004. 